Obere Extremität 2021 · 16:54-58 https://doi.org/10.1007/s11678-020-00586-w Received: 15 December 2019

Accepted: 29 June 2020

Published online: 3 August 2020

(c) The Author(s) 2020

Christian Festbaum ${ }^{1}$ (D) - Victor Danzinger ${ }^{1}$. William Kibler ${ }^{2}$ Pascal Boileau ${ }^{3}$. Simon Lambert ${ }^{4}$ - Giuseppe Porcellini ${ }^{5}$. Christian Gerhardt ${ }^{6} \cdot$ Markus Scheibel $^{7}$. Mark Tauber $^{8} \cdot$ Mathias Wellmann $^{9} \cdot$ Christiane Adamczewski $^{10}$. Seraina VitalSchmid" ${ }^{11}$ Philipp Moroder

'Center for Musculoskeletal Surgery, Charité-Universitätsmedizin Berlin, Campus Virchow Klinikum, Berlin, Germany

${ }^{2}$ Shoulder Center of Kentucky, Lexington Clinic, Lexington, USA

${ }^{3}$ Institut Universitaire Locomoteur \& Sport, Côte d'Azur University, Nice, France

${ }^{4}$ Department of Trauma and Orthopaedic Surgery, University College London Hospital, London, UK

${ }^{5}$ Orthopaedic and Trauma Unit, University of Modena and Reggio Emilia, Modena, Italy

${ }^{6}$ Department of Traumatology and Hand Surgery, ViDia Clinics, Karlsruhe, Germany

${ }^{7}$ Department of Shoulder and Elbow Surgery, Schulthess Clinic, Zürich, Switzerland

${ }^{8}$ ATOS Clinic Munich, Munich, Germany

${ }^{9}$ Department of Orthopaedic Surgery, Medical School Hannover, Hannover, Germany

${ }^{10}$ Rehazentrum Virchow GbR, Charité-Universitätsmedizin Berlin, Berlin, Germany

${ }^{11}$ Department of Shoulder and Elbow Physiotherapy, Schulthess Clinic, Zürich, Switzerland

\title{
Delphi survey on conventional conservative treatment of functional posterior shoulder instability
}

posterior shoulder instability (B1) and structural posterior shoulder instability (B2; [16]). Functional PSI can either be a controllable or a non-controllable condition depending on the patient's ability to willfully control the instability episodes [15].

While controllable functional PSI requires only patient counseling, non-controllable functional PSI can be challenging to treat. Surgical stabilization attempts are not recommended as they often lead to excessive pain as well as increased functional restriction, and might even result in early degenerative changes [4-6, 12, 18]. Conventional physiotherapy is considered to be the treatment option of choice $[1,6]$. However, physiotherapy often has limited success unless very specific and intensive training programs are applied by specially trained experts [18]. Unfortunately, no consensus on the treatment of functional PSI exists. In order to analyze the benefits and potentially improve the outcome of conventional physiotherapy in the treatment of this particular pathology, a standardized treatment guideline is required.

The goal of this study was to find an expert consensus on the treatment standard for non-controllable functional PSI. The consensus reached should not only provide a treatment recommendation but also specify a starting point for further comparative studies and successive improvement of the current treatment standard of this challenging pathology.

\section{Material and methods}

Based on the very limited available literature on the subject of interest, a local expert committee including two physiotherapists and two shoulder surgeons developed a standardized training program for the treatment of functional PSI [1, 2, $6,8-10,13,14,19]$. The defined exercises of the program focus on strengthening the scapula retractors and external rotator muscles since their hypoactivity plays a major role in PSI [7]. The training program consisted of three different levels 


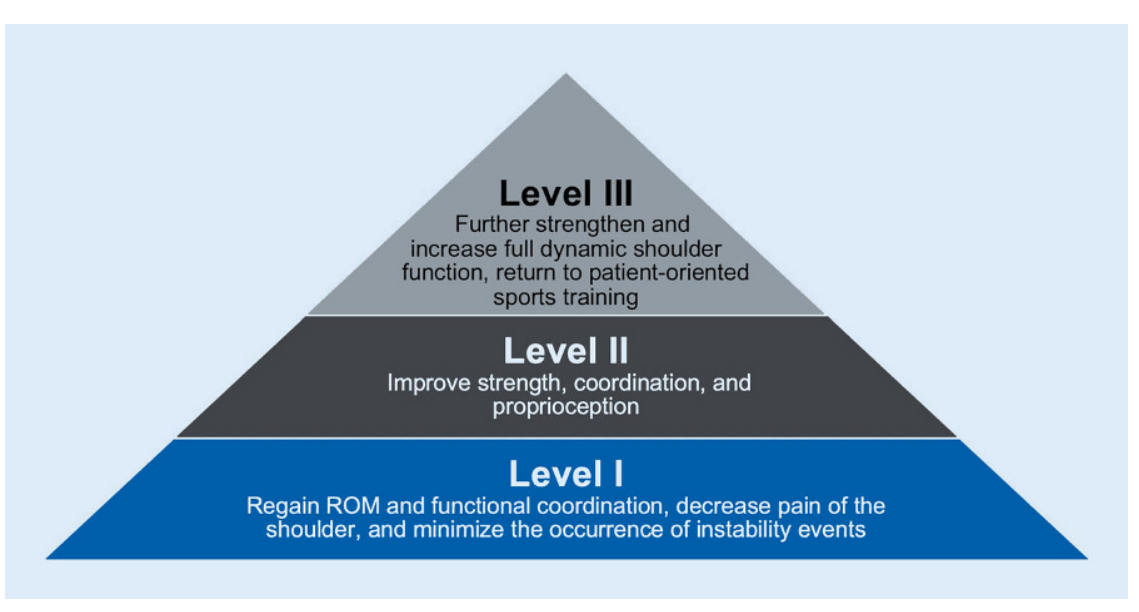

Fig. $1 \Delta$ Stepwise structure of the physiotherapy plan. ROM range of motion

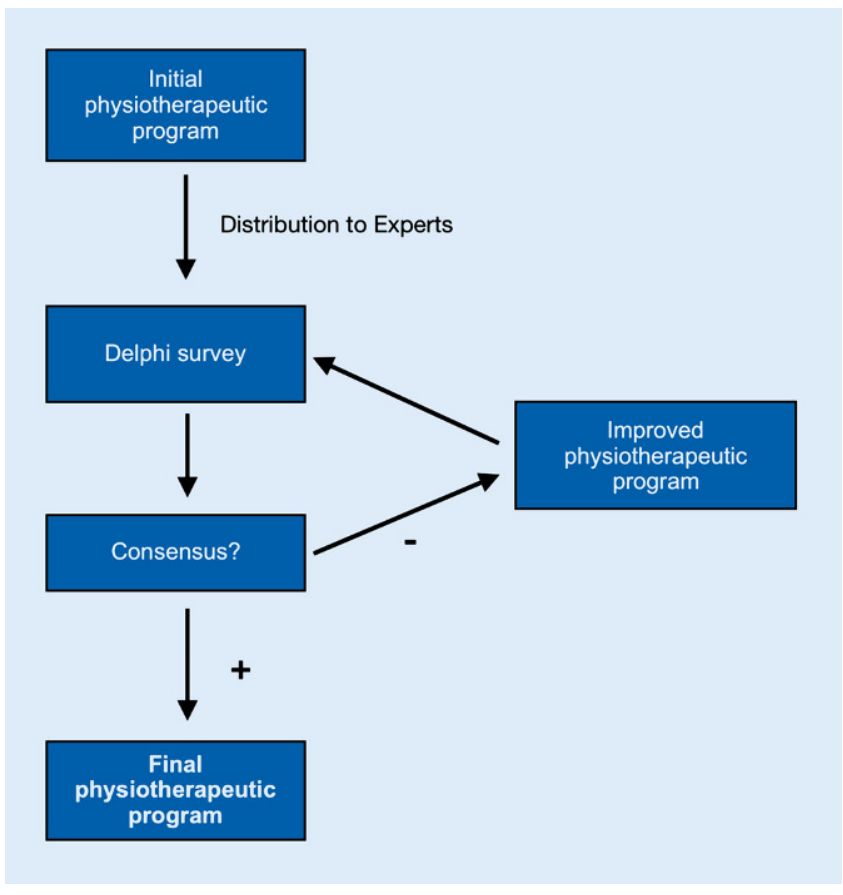

Fig. $2<$ Iterative structure of the Delphi survey, illustrating the repetitive feedback process

of exercises with increasing difficulty and complexity (• Fig. 1).

Starting exercises in level I aim to regain range of motion (ROM) and functional coordination, to decrease pain in the shoulder, and to minimize the occurrence of instability events. A painless full ROM should be established before startinglevel II. The aim oflevel II is to improve strength, coordination, and proprioception by performing mild-to-moderate resistance exercises with a high number of repetitions. In level III, the patient should further strengthen and increase full dynamic shoulder function and return to patient-oriented sports training (POST). should be feasible for home practice. Therefore, we aimed for a program that can be accomplished via self-training at home as well. Additionally, most of the exercises should be practicable with only basic work-out tools such as a resistance band and a gymnastics ball. The treatment minimum was set at three times per week over a period of 6 weeks.

The resulting exercise program was subjected to a Delphi survey, which is a standardized procedure to find consensus among experts in an iterative communication process and is especially used for issues where knowledge is incomplete [3]. The benefit from subsequent rounds of feedback distinguish the Delphi process from simple opinion surveys. The method is repeated until complete agreement is reached and should include at least two or more "rounds" in a multistage process [3].

Experts on functional shoulder instability, as expressed by their research activity in this special field, were invited to participate in this Delphi survey. Each expert also involved his or her team in the survey process. The final expert board consisted of nine members. Each participant received an online invitation to review the proposed standardized exercise program and to suggest any changes as deemed necessary. No suggested changes were rated as "total agreement" while every type of additional information or any suggested changes were considered as "total disagreement." To ensure high levels of agreement, the consensus threshold was set at $95 \%$ for each individual exercise. Every suggested change was incorporated into the next version of the exercise program, which was then re-submitted to all participants. There were no dropouts over the course of the Delphi survey, leading to a response rate of $100 \%$ for each round (• Fig. 2).

\section{Results}

The results of the first survey round showed acceptable agreement for most parts of the exercise program; however, there were some points of disagreement too. The lowest rate of consensus was observed for exercises of level I (83\%), followed by level II (90\%), and level III 
Obere Extremität 2021 · 16:54-58 https://doi.org/10.1007/s11678-020-00586-w

(c) The Author(s) 2020

C. Festbaum · V. Danzinger · W. Kibler · P. Boileau · S. Lambert · G. Porcellini · C. Gerhardt · M. Scheibel · M. Tauber · M. Wellmann · C. Adamczewski · S. Vital-Schmid · P. Moroder

\section{Delphi survey on conventional conservative treatment of functional posterior shoulder instability}

\section{Abstract}

Background. Posterior shoulder instability is caused by structural or functional defects. While the former are mostly treated surgically, physiotherapy is considered the treatment of choice in functional shoulder instability. However, it often has limited success unless very specific and intensive training programs are applied by trained experts. Currently, there is no consensus on the treatment of functional posterior shoulder instability.

Objective. To improve treatment of this pathology, a standardized treatment recommendation is required to serve as a guideline for physiotherapy. The aim of this study was to establish expert consensus for treatment recommendations for functional posterior shoulder instability.
Design. The Delphi survey technique was employed.

Methods. A standardized training program for treatment of functional posterior shoulder instability was developed by a local expert committee. Two rounds of an online Delphi survey were then conducted. The panel of the Delphi survey comprised nine leading scientific experts in the field of functional shoulder instability who treat patients with shoulder-related problems conservatively and operatively.

Results. The response rate was 100\% and there were no dropouts. The final program consists of three groups of exercises with increasing difficulty. The exercises are mostly easy to perform and focus on the scapula-retracting muscles and the muscles responsible for external rotation of the shoulder. The treatment program should be executed under the supervision of a therapist at the beginning and later may be performed by the patients themselves.

Conclusion. Consensus on a new exercise guideline dedicated to the treatment of functional posterior shoulder instability was achieved. This guideline should not only help to treat this challenging pathology but also provide a starting point for further scientific research and ongoing improvement.

\section{Keywords}

Scapula - Joint instability - Physical therapy modalities - Guideline $\cdot$ Treatment recommendation

\section{Delphi-Verfahren zur konventionellen konservativen Therapie der funktionellen hinteren Schultergelenkinstabilität}

\section{Zusammenfassung}

Hintergrund. Die hintere Schulterinstabilität kann durch strukturelle Schäden oder ein funktionelles Defizit bedingt sein. Während Erstere vorwiegend chirurgisch angegangen werden, gilt bei funktionellen Defiziten Physiotherapie als Mittel der Wahl. Jedoch hat diese oft nur begrenzten Erfolg, sofern nicht überaus spezifische und intensive Trainingspläne von gut ausgebildeten Trainern angewendet werden. Aktuell besteht kein Konsens hinsichtlich der Behandlung der funktionellen hinteren Schulterinstabilität. Ziel. Um die Behandlung dieser speziellen Erkrankung zukünftig zu verbessern, bedarf es eines standardisierten Behandlungsplans als Leitlinie für die Physiotherapie. Ziel dieser Studie war die Etablierung eines Expertenkonsenses zur Behandlungsempfehlung für die funktionelle hintere Schultergelenkinstabilität.
Design. Es wurde die Delphi-Methode angewendet.

Methoden. Ein standardisierter Trainingsplan für diese Indikation wurde von einem Expertenteam erarbeitet. Dieser Trainingsplan durchlief 2 Runden in einem OnlineDelphi-Verfahren. Teilnehmer des DelphiVerfahrens waren 9 führende Experten auf dem Gebiet der konservativen und operativen Therapie der funktionellen hinteren Schultergelenkinstabilität.

Ergebnisse. Die Antwortrate in dem Delphi-Verfahren betrug $100 \%$, es gab keine Abbrecher. Der finale Trainingsplan untergliedert sich in 3 Gruppen von Übungen mit jeweils schrittweise ansteigender Komplexität. Die Übungen sind größtenteils leicht durchzuführen und richten sich auf die schulterblattretrahierende Muskulatur und die Außenrotatoren des Schultergelenks.
Das Programm sollte zu Beginn noch unter therapeutischer Kontrolle durchgeführt werden, um eine exakte Durchführung zu gewährleisten. In späteren Stadien erfolgt es dann eigenständig durch die Patienten. Schlussfolgerung. Ein Konsens hinsichtlich eines neuen Trainingsplans als Richtlinie speziell für die Behandlung der hinteren funktionellen Schulterinstabilität wurde erreicht. Dieser Trainingsplan soll dabei helfen, diese anspruchsvolle Erkrankung zu behandeln und außerdem den Startpunkt für weiterführende wissenschaftliche Untersuchungen bilden.

Schlüsselwörter

Skapula · Gelenkinstabilität · Physiotherapiemodalitäten · Leitlinie · Behandlungsempfehlung
(96\%). The degree of agreement regarding the individual exercises is displayed in - Table 1.

The main point of criticism was the use of open-chain exercises in level I as they are too difficult to perform for patients with functional PSI due to their oftenpoor muscle activation and propriocep- tive insufficiency. It was suggested to begin with closed-chain exercises, which complies better with the aim of a stepwise training procedure with increasing difficulty. Therefore, level I exercises were mostly changed to so-called closed-chain exercises, in which the terminal link of the chain is constrained or immobilized in a fixed position. Besides these modifications, additional exercises for level II were implemented targeting a better improvement of strength, coordination, and proprioception.

In the second survey round there was $100 \%$ agreement on the structure of the program and all the exercises involved. 
Table 1 Degree of agreement for each exercise after the first two rounds of the Delphi survey

Agreement (\%)

\section{Version 1}

Levell

1: Elevation with resistance band

71.4

2: Scapula pinch

71.4

3: Isometric external rotation

100.0

4: Seated external rotation

85.7

5: Plank in quadruped position

85.7

Level II

1: Elevation with resistance band

85.7

2: Concentric external rotation

85.7

3: Standing row

85.7

4: Eccentric external rotation

100.0

5: Wall scapular push-up

100.0

6: Contralateral arm raises

85.7

Level III

1: Plyometric exercises

100.0

2: Patient-oriented sports training (POST)

100.0

3: Reverse butterfly

100.0

4: Eccentric external rotation

100.0

5: Scapular push-up

100.0

6: Swiss ball squat thrust

85.7

7: Side-lying plank

85.7

Version 2

Levell

1: Elevation with lateral resistance ("lateral wall slide")

100.0

2: Two-handed axial-loaded elevation

100.0

3: Prone retroflexion ("I")

100.0

4: Prone shoulder external rotation in $20^{\circ}$ abduction ("W")

100.0

5: Isometric external rotation

100.0

Level II

1: Elevation with resistance band

100.0

2: Prone horizontal external rotation ("L")

100.0

3: Prone horizontal abduction and external rotation (" $\mathrm{T}$ ") 100.0

4: Concentric external rotation with trunk rotation $\quad 100.0$

5: Concentric external rotation in $90^{\circ}$ abduction $\quad 100.0$

$\begin{array}{ll}\text { 6: Standing one-handed row } & 100.0\end{array}$

\begin{tabular}{l|l} 
7: Eccentric external rotation & 100.0
\end{tabular}

\begin{tabular}{l|l} 
8: Wall scapular push-up & 100.0
\end{tabular}

9: Ball circles against wall $\quad 100.0$

10: Contralateral arm raise with ipsilateral leg raise $\quad 100.0$

Level III

1: Plyometric exercises

100.0

2: Patient-oriented sports training (POST)

100.0

3: Reverse butterfly

100.0

4: Concentric low row

100.0

5: Diagonal external rotation

100.0

6: Scapular push-up

\section{Discussion}

The main goal of most existing treatment strategies is a progressive strengthening of the deltoid and rotator cuff muscles including stabilization of the scapula. According to the literature, the specific programs differ widely and often are not specifically dedicated to the treatment of functional PSI but are instead aimed at all types of glenohumeral instabilities $[1,11$, 18]. Therefore, this project focused on developing a training program that would serve as a recommendation specifically dedicated to the treatment of functional PSI (see Online Supplement 1: "Exercise program").

It consists of three groups of exercises with increasing difficulty that are executed under the supervision of a therapist to begin with and later can potentially be performed by the patients themselves. The exercises focus on the scapula-retracting muscles and the muscles responsible for external rotation of the shoulder, both of which are important to stabilize the humeral head against posterior dislocation [6]. The training begins with general closed-chain exercises relatively easy to perform and increases the level of difficulty and complexity in a stepwise manner as patients improve. Toward the end of the training, patient-specific exercises involving individual sports-specific movement patterns are performed such as, for example, throwing a ball.

Generally, it is difficult to define an exact amount of recommended training time and cycles, since the medical requirements vary individually as does the insurance coverage of expenses. However, we recommend a therapy plan consisting of three sessions of treatment per week over a period of 6 weeks. In this context, a session is defined as $60 \mathrm{~min}$ of exercises. In the beginning of the program, the exercises should be performed under the supervision of specifically trained physiotherapists. Toward the end of the program, autonomous implementation should be attempted to ensure long-term therapy at home in order to prevent recurrence.

Finally, it must be stated that the success of a dedicated exercise program depends on the correct diagnosis. There- 
fore, it is of crucial importance to clearly distinguish posterior FSI from posterior instability caused by structural defects and to identify the true direction of instability, which is not always as easy as it seems $[15,17]$.

\section{Limitations}

This Delphi survey has a few limitations. First, the number of experts involved in the Delphi survey was limited. Second, the survey was completed right after the minimum number of rounds required in a Delphi survey. Involving a larger committee and completing more rounds would possibly lead to a slightly different treatment program. However, there was a complete consensus after two successive rounds. A third round would not have changed or improved the program.

\section{Practical conclusion}

\section{- We propose a new and specifically dedicated exercise recommendation for the treatment of functional posterior shoulder instability based on a consensus among experts in this field. \\ - This guideline should not only help to treat this challenging pathology but also provide a starting point for further scientific research and ongoing improvements.}

\section{Corresponding address

Christian Festbaum
Center for Muscu-
loskeletal Surgery,
Charité-Universitätsmedizin
Berlin, Campus Virchow
Klinikum
Augustenburger Platz 1,
13353 Berlin, Germany
christian.festbaum@charite.de

Funding. We would like to thank the Deutschen Forschungsgemeinschaft (DFG, German ResearchFoundation) for the financial support.

Funding. Open Access funding provided by Projekt DEAL.

\section{Compliance with ethical guidelines}

Conflict of interest. C. Festbaum, V. Danzinger, W. Kibler, P. Boileau, S. Lambert, G. Porcellini, C. Gerhardt, M. Scheibel, M. Tauber, M. Wellmann, C. Adamczewski, S. Vital-Schmid, and P. Moroder declare that the authors themselves, their immediate family, or any research foundation with which they are affiliated did not receive any financial payments or other benefits from any commercial entity related to the subject of this article. No outside funding or grants were obtained for this study.

For this article no studies with human participants or animals were performed by any of the authors. All studies performed were in accordance with the ethical standards indicated in each case.

Open Access. This article is licensed under a Creative Commons Attribution 4.0 International License, which permits use, sharing, adaptation, distribution and reproduction in any medium or format, as long as you give appropriate credit to the original author(s) and the source, provide a link to the Creative Commons licence, and indicate if changes were made. The images or other third party material in this article are included in the article's Creative Commons licence, unless indicated otherwise in a credit line to the material. If material is not included in the article's Creative Commons licence and your intended use is not permitted by statutory regulation or exceeds the permitted use, you will need to obtain permission directly from the copyright holder. To view a copy of this licence, visit http://creativecommons.org/licenses/by/4.0/.

\section{References}

1. Burkhead WZ Jr., Rockwood CA Jr. (1992) Treatment of instability of the shoulder with an exercise program. J Bone Joint Surg Am 74:890-896

2. Dexel J, Kopkow C, Kasten P (2014) Skapulothorakale Dysbalancen bei Überkopfsportlern: Ursachen und Therapiestrategien

3. Hasson F, Keeney S, Mckenna H (2000) Research guidelines for the Delphi survey technique. J Adv Nurs 32:1008-1015

4. Hawkins RJ, Koppert G, Johnston G (1984) Recurrent posterior instability (subluxation) of the shoulder. JBone Joint Surg Am 66:169-174

5. Huber H, Gerber C (1994) Voluntary subluxation of the shoulder in children. A long-term followup study of 36 shoulders. J Bone Joint Surg Br 76:118-122

6. Jaggi A, Lambert S (2010) Rehabilitation for shoulder instability. Br J Sports Med 44:333-340

7. Jaggi A, Noorani A, Malone A et al (2012) Muscle activation patterns in patients with recurrent shoulder instability. Int J Shoulder Surg 6:101-107

8. Kibler WB (1998) The role of the scapula in athletic shoulder function. Am J Sports Med 26:325-337

9. Kibler WB, Livingston B (2001) Closed-chain rehabilitation for upper and lower extremities. J Am Acad Orthop Surg 9:412-421

10. Kibler WB, Sciascia A (2016) The role of the scapula in preventing and treating shoulder instability. Knee Surg Sports Traumatol Arthrosc 24:390-397

11. Kiss J, Damrel D, Mackie A et al (2001) Nonoperative treatment of multidirectional shoulder instability. Int Orthop 24:354-357
12. Kuroda S, Sumiyoshi T, Moriishi J et al (2001) The natural course of atraumatic shoulder instability. JShoulderElbow Surg 10:100-104

13. Mcintyre K, Belanger A, Dhir J et al (2016) Evidencebased conservative rehabilitation for posterior glenohumeral instability: a systematic review. Phys Ther Sport 22:94-100

14. Merolla G, De Santis E, Cools AM et al (2015) Functional outcome and quality of life after rehabilitation for voluntary posterior shoulder dislocation: a prospective blinded cohort study. Eur J Orthop Surg Traumatol 25:263-272

15. Moroder P, Danzinger V, Maziak N et al (2018) Characteristics of functional shoulder instability. JShoulder Elbow Surg 29(1):68-78

16. Moroder P, Danzinger V, Minkus M et al (2018) The $A B C$ guide for the treatment of posterior shoulder instability. Orthopäde 47:139-147

17. Robinson CM, Aderinto J (2005) Recurrent posterior shoulder instability. J Bone Joint Surg Am 87:883-892

18. Takwale VJ, Calvert P, Rattue H (2000) Involuntary positional instability of the shoulder in adolescents and young adults. Is there any benefit from treatment? JBone Joint Surg Br 82:719-723

19. Wilk KE, Macrina LC, Reinold MM (2006) Non-operative rehabilitation for traumatic and atraumatic glenohumeral instability. N Am J Sports Phys Ther 1:16-31 